\title{
LOS SENDEROS ALTERNATIVOS DEL TERRITORIO EDUCATIVO: REFLEXIONES DE UN TRANSEUNTE PEDAGÓGICO QUE SE PERDIÓ SIN PERMISO
}

The alternatives path in the educative territory: reflexions of a pedagogical passerby who got lost without permission

Os caminhos alternativos do território educativo: reflexões de un transeunte pedagógico que se perdeu sem pedir licença

\section{Simón Iribarren Poyanco}

Territorio Educativo Libre Vertiente, La Serena, Chile. Fono: +56 9 66282262. Correo electrónico: saipelon@gmail.com

\section{Resumen}

La escuela trata de controlar los procesos educativos con un mapa estático, como si aprender se tratara de caminar por una carretera pavimentada y recta, pero la experiencia indica que al transitar por otros senderos lejos de esa ruta rígida, en experiencias educativas fuera de la escuela y dentro de la escuela, se va aprendiendo a favorecer la propensión natural al aprendizaje del ser humano, a perderse explorando, para aprender a vivir en la incertidumbre que es la vida, y en esa experiencia se aprende de manera más fluida y significativa. En ese camino van emergiendo nuevas preguntas y nuevos desafíos, se encuentran nuevos territorios que reafirman los diagnósticos negativos y que enseñan a permanecer con una actitud atenta, abierta y reflexiva. Experiencias de aula que permiten reflexionar sobre la crisis de la escuela y de las oportunidades que nos ofrecen las comunidades si estamos atentos a percibirlas. Crear lazos de confianza, relaciones que respeten y validen la emoción de los otros y otras junto a esfuerzos por repensar el tiempo y el espacio escolar, son algunas de las conclusiones para poder vivir transformaciones profundas en la escuela, que por cierto solo se pueden comenzar sin permiso. 
Palabras clave: propensión a aprender; tiempo educativo; reflexión pedagógica.

\begin{abstract}
The school controls the educational processes as a static map, as if the learning process was based on walking through a paved and straight road. But the experience indicates that, when moving towards different paths, far from this inflexible route, in educational experiences in and outside schools, one can enable more easily the natural learning propulsion of the human being, as well as getting lost and learning how to live with life's incertitude. In this experience people learn in a lithely and meaningful way. In this path, new questions and challenges emerge, new territories converges to prove the negative diagnosis and to reinforce the need to remain with a careful, opened and thoughtful attitude. Classroom experiences allow thinking about school crisis and also about community opportunities if we are careful and opened towards it. Creating trust bonds and relationships that respect and values others emotions, with an effort to rethink scholar space and time, are some necessary conclusions to achieve deep school transformations which can only begin without permission.
\end{abstract}

Key-words: learning propulsion; educational time; pedagogical reflection.

\title{
Resumo
}

A escola controla os processos educativos como um mapa estático, como se aprender se tratasse de caminhar por uma estrada pavimentada e reta. Mas, a experiência indica que ao transitar por outros caminhos distantes dessa rota rígida, em experiências educativas fora e dentro da escola, se aprende a favorecer a propensão natural ao aprendizado de ser humano, a perder-se explorando, a viver na incerteza que é a vida e, nessa experiência, se aprende de maneira mais fluida e significativa. Nesse caminho vão emergindo novas perguntas e novos desafios, são encontrados novos territórios que reafirmam diagnósticos negativos e que, ao mesmo tempo, ensinam a permanecer com uma atitude atenta, aberta e reflexiva. Experiências em classe permitem refletir sobre a crise da escola e sobre oportunidades oferecidas pelas comunidades, se estamos atentos a percebê-las. Criar laços de confiança, relações que respeitem e validem a emoção de outros e outras, junto a esforços por repensar 
o tempo e o espaço escolar, são algumas das conclusões para poder viver transformações profundas na escola que, de certo, só podem começar sem que se peça licença. Palavras chave: propensão a aprender; tempo educativo; reflexão pedagógica.

\section{Dejar la carretera para ir a los senderos}

Caminar es una actividad que me fascina y me ocupa desde de temprana edad, pero no el cotidiano caminar por calles y pasillos, me refiero a perderme, a caminar entre cerros, bosques y dudas, que por lo general se transforman en bosques y cerros de dudas. Mis primeros años los viví en la escuela, literalmente aprendí a caminar entre las sillas de la escuela, gracias a que mi padre y madre eran profesores de escuelas rurales, de esas en las que la casa del profesor y la escuela son la misma cosa. Pero esas escuelas siempre estuvieron ubicadas a los pies de una montaña y cerca de un río. Por ocio y una irremediable tendencia a la reflexión en movimiento, acostumbré desde pequeño a subir cerros y a perderme en quebradas, a bañarme en ríos y a subir árboles. No habían tardes iguales, no habían experiencias que se repitieran, pero muchas de esas tardes y experiencias dejaron huellas en mi ser que nunca se borrarán (sobre todo las cicatrices).

Era realmente divertido tener esa ilusión de certeza de que mis laboriosos y comprometidos padre y madre no llegarían a casa hasta casi entrada la noche, pero que confiaban que si me llegase a pasar algo en esas pequeñas comunidades en las que vivíamos se enterarían rápidamente y sería acogido y cuidado por cualquier vecino. Y como creía siempre que no llegarían temprano a casa, me dedicaba a salir, sin permiso, a explorar el mundo, sin mapa, sin ocupar los mismos caminos de siempre. Desde las alturas de las montañas puedes verlo todo, ver la escuela en el corazón del poblado, ver cómo se movían esos pequeños puntitos, yendo y viniendo, y ahí comencé a preguntarme sobre los patrones y la capacidad de comprender como funciona todo. Creaba mis teorías desde esa posición de observador, pero luego volvía, a vivir junto a los puntitos que desde esta nueva altura tenían rostros, nombres y se ven más impredecibles. ¿Me proponía subir a aprender algo? 
No. ¿Aprendía algo viviendo de esa manera? Mucho. Sin querer y sin permiso, con esa incontenible propensión al aprendizaje que tenemos los humanos.

El que se pierde sin ruta, siempre debe estar atento, con mente y corazón abiertos, oír tus miedos que son sabios y de ayuda, pero es necesario actuar valientemente para no quedarte quieto. El que se pierde sin ruta sabe que no conoce el camino, pero sabe que los cerros son parecidos, que el viento, el sol, los ríos, las plantas y los animales se comportan de maneras similares en patrones caóticos que permitirían, si uno está dispuesto a observar y aprender de cada experiencia, a caminar con seguridad en esos territorios inexplorados, a caminar con seguridad de que la incierto ocurrirá y que hay que seguir atento, con mente y corazón abiertos.

Podría decir que mi vida fue marcada profundamente por estas experiencias e inevitablemente mi quehacer pedagógico, se asemeja bastante a esos viajes sin mapa, a esos viajes atentos y reflexivos, a esos viajes sin permiso, pero que se desarrollaban en la confianza, sin más miedo que aquel miedo instintivo que te advierte de los peligros.

Actualmente me encuentro formando parte de un proyecto educativo llamado Territorio Educativo Libre, el que obviamente no está reconocido por el ministerio de educación, ya que a diferencia de mis padres y la comunidad del pueblo en el que crecí, ellos no se caracterizan por confiar ni cuidar, por lo que no les parece buena idea que nos adentremos en el territorio educativo sin su mapa (Calvo, 2008). Este proyecto acoge a más de treinta niños, niñas, jóvenes de entre cinco y dieciocho años, junto a sus familias y a cuatro educadores. Un espacio organizado para que en él se desarrollen actividades pedagógicas, existan tiempos educativos y se conforme una comunidad unida por la búsqueda de un vivir armonioso y feliz en la etapa "escolar" de los niños y niñas. Nos categorizan como una "escuela alternativa", pero por ahora ni siquiera nos identificamos con el nombre de escuela. ¿Cómo llegué hasta acá? Recorriendo esos senderos alternativos que entran y salen de los caminos establecidos, con un caminar decidido y un ritmo pausado. Decidido a vivir en un mundo con esperanza, con felicidad, con coherencia, en el que la educación lleva a la autorrealización y a la conformación de comunidades que 
conserven su bienestar. A un ritmo que espera que los procesos se den naturalmente, sin presiones, aunque si con intenciones.

Paso a relatar algunos episodios en este viaje, para compartirles mis experiencias y que hagan con ellas lo que estimen conveniente, solo pido que no pongan expectativas sobre ellas, que las lean y que desde el sintonizar o no con lo que he ido aprendiendo, puedan reflexionar sobre su ser, hacer y suceder.

\section{La constante sensación de que algo anda mal}

\subsection{Diagnósticos como estudiante}

Es común escuchar a jóvenes decir cosas como "a mi mamá se le olvidó que alguna vez fue niña”, y creo que ese fenómeno de escasez de memoria, o memoria selectiva, nos ocurre también a los educadores. Cuando pensé en eso, comencé la búsqueda de recuerdos de mi niñez en esa escuela rural, en ese liceo municipal, ya que si quería entender a los niños, niñas y jóvenes con los que trabajaría, despertar los procesos empáticos debía ser, a mi parecer, un proceso deliberado y consciente.

¿Por qué algo que disfruto tanto como aprender, no lo disfruto en un lugar cuyo objetivo es que aprenda? Claramente esta pregunta no logró su forma textual hasta hace pocos años, pero la sensación me recorría durante mis años de estudiante tanto en la escuela como en la etapa de enseñanza media. ¿Qué intuía en esos momentos? ¿Percibía las incongruencias entre los discursos pedagógicos y las prácticas? ¿Resentía la evidente desconexión de las formas escolares con las propias formas de aprender? Lo que si recuerdo claramente era que los tiempos previamente programados, muy pocas veces coincidían con mis tiempos y ritmos. Siempre que comenzaba a motivarme con un tema se acaba el tiempo de la clase de esa asignatura (esto principalmente en artes y ciencias), quedaba con la sensación de querer seguir, explorar el tema o continuar la actividad hasta que ya no quedaran más posibilidades, la necesidad de saciar la curiosidad. Pero no, había una campana que marcaba la entrada y salida de los temas, como un semáforo que marca el ritmo de los autos en las calles, en esos caminos rectos y con sus respectivas filas y filas de vehículos con choferes inconformes. Sentía que necesitaba ser más un transeúnte que un 
conductor, alguien que se hace camino al andar y no el que sigue las normas del tránsito y los caminos prestablecidos. ¿Cómo sería una escuela sin campanas? ¿Sin horarios? ¿Sin asignaturas? ¿Creen que uno no se da cuenta de que algo anda mal con la forma de enseñar? ¿Por qué algo entretenido como muchas temáticas de mi interés se volvían tan aburridas? Era incomprensible, y también insoportable. Las dificultades para aprender no solo emergían de la poca comprensión de los ritmos y tiempos, sino también desde el alejamiento con las formas de aprender y de las motivaciones de cada niño o niña. ¡Hay que cambiar la forma de hacer clases! Habría dicho en mi época escolar ¡Es necesario transformar la forma de organizar el espacio y tiempo educativo! Creo que sería su reedición en mi época de profesor.

Eran tantas las cosas que se sentían extrañas en la escuela, ¿Por qué a mis compañeros se les complicaba tanto el proceso escolar? ¿Por qué niños y niñas tenían que trabajar? ¿Por qué en el liceo nos separaban por estrato socioeconómico para formar los cursos? ¿Por qué mi curso tenía claramente un mejor "rendimiento académico" que los demás si teníamos a los mismos profesores? Y así un sinfín de dudas que voy reflexionando en este caminar por el territorio educativo, dudas que solo van aportando a mi conocimiento de cómo funciona el sistema escolar y entregándome pistas sobre como bordear los caminos establecidos y atravesar senderos con mayores probabilidades de revertir el curso que lleva la escuela.

La vida de universitario estudiando pedagogía no me ofreció una experiencia como estudiante muy diferente a la que había vivido en la escuela y liceo, solo asignaturas para las que había que estudiar para la prueba y con eso bastaba. ¿Cómo es posible que la formación de los profesionales que estarán a cargo de los procesos educativos de las generaciones que vienen pueda permitir que alguien pueda egresar con el título profesional sin haber transformado un ápice su forma de enseñar o sus formas de concebir el aprendizaje o la educación? ¿Por qué no se piensa un sistema de formación de educadores que tenga un enfoque fuertemente profesionalizante y con un trabajo exigente en los aspectos intra e interpersonales? 
Eso me cuestionaba a medida que me enseñaban a rellenar el libro de clases correctamente o a enseñar de variadas maneras un contenido ¿Pondría usted el presente y futuro en manos de profesionales que son formados en ese sistema? La formación para un solo tipo de contexto escolar, y además desde perspectivas teóricas muy incoherentes me hacía sentir que lo que promovía ese espacio universitario, tremendamente escolarizado (Calvo, 2008), no me serviría demasiado para educar de nuevas maneras, pero si para reproducir de manera más perfeccionada las mismas prácticas. ¿Cómo debería ser la formación de educadores? ¿Cómo desescolarizar los espacios universitarios? ¿Qué responsabilidad tiene la universidad pública en la educación escolar? Dudas y más dudas, pero todo me indicaba que el camino que me señalaban llegaría en no mucho andar a un precipicio. Era hora de empezar a buscar alternativas.

Desde el plano político los diagnósticos no fueron más alentadores respecto a ese pavimentado camino recto hacia el precipicio. Fueron años muy movidos los que me tocó vivir, desde el 2006 hasta el 2011. Estando en representaciones regionales y nacionales uno logra percibir la existencia de personas con tanto poder y poca consciencia que pueden echar por tierra las ideas mejor concebidas y las intenciones más bondadosas. Todo indicaba que el viraje hacia otras direcciones en el devenir de la educación en Chile, no ocurriría por decisión o motivación de quienes hoy toman las decisiones en el Ministerio de Educación, el Congreso o el Gobierno. Si vamos a hacer algo, probablemente tenga que ser sin permiso.

\subsection{Diagnósticos como profesor}

Mi experiencia como profesor en escuelas oficiales y formales fue breve temporalmente, pero muy intensa, lo suficiente como para dejarme con algunas ideas de por qué se esa institución hoy enfrenta una crisis importante, que se manifiesta en el agobio docente, en una gran cantidad de reformas y millonarios presupuestos invertidos en supervisión y en el triste número de niños y niñas que no se desarrollan plenamente, aumentando las cifras del mal llamado fracaso escolar. ¡En el fracaso escolar no fracasan los niños! ¡Fracasamos los adultos! 
En las escuelas resentí mucho la desconexión y la cantidad abrumadora de obstáculos para poder trabajar con el equipo docente. La necesidad de retroalimentación, de discusión pedagógica, de disoñar (Calvo, 2008) la escuela en conjunto, todo esto se veía sobrepasado por la cantidad de trabajo que debe hacer cada uno y la estrechez del horario con el que contamos para poder hacer las cosas de manera más profesional y colaborativa. Recordé por esos días la autopromesa de nunca trabajar más de 30 horas semanales, ya que predecía un futuro muy atareado y con horas de trabajo después de clases. Promesa difícil de sostener, las necesidades de las escuelas hacen que tengan que maximizar las horas de contrato para no costear más profesores, lo que hace una complementación perfecta con el hecho de que los sueldos son bajos. La suma de todo esto, es visible en equipos desunidos, en escasa reflexión pedagógica, en un agobio laboral que enferma a profesores y profesoras, pero que perversamente, va tentando por seguir el camino trazado, y no alejarse mucho de esa ruta, ya que quienes evalúan y acreditan solo conocen un camino y no podrán comprender en sus observaciones anacrónicas como al transitar por los senderos caóticos de la educación los aprendizajes pueden llegar a ser muy potentes y las transformaciones sociales hacia un bienestar comunitario no tan lejanas. ¿Esta es la única forma posible de organizar una unidad educativa?

\section{La constatación de que algo anda mal}

Los aspectos anteriormente mencionados como obstáculos, desafíos, dudas, fueron siendo reafirmados o esclarecidos con el pasar de las experiencias educativas que fui viviendo. Uno de los momentos que suelo recordar más a la hora de analizar las trabas que le ponemos a la propensión a aprender, es cuando una profesora golpea la puerta de mi oficina en una escuela municipal para pedirme que "por favor atienda a un estudiante que está dando una prueba porque no sé qué más hacer con él". Yo accedo a ayudarle pero antes le pregunto algunas cosas al niño en presencia de la profesora: ¿De qué es la prueba? De los romanos ¿Y qué problema tienes? Es que no sé ¿Pero, que te preguntan en la prueba? La pregunta dice: Qué importancia tenían los caminos para los romanos. ¿Y entiendes la pregunta? No ¿Qué parte de la pregunta no logras entender? No sé ¿Conoces la palabra importancia? Sí, es lo que importa, lo que sirve ¿Y sabes lo que es camino? No, eso no lo 
sé. Frente a eso no pude si no sorprenderme y comenzar una mediación para que esa dificultad lingüística no frustrara sus procesos de aprendizaje ni invalidara su capacidad lógica por una privación cultural tan inmensa y evidente. ¿A qué palabra se parece camino? A caminar ¿Y cómo se llama el lugar por donde uno camina? Vereda. Cierto, y cuando no hay ni veredas ni calles, cómo cuando uno va a un cerro o un lugar de tierra ¿Por dónde caminas? Por las huellas. Muy bien, otra forma de llamarle a las huellas o calles, es camino. ¿Y para qué sirve un camino o huella? Para caminar, para llegar de un lado a otro. Muy bien, entonces, si los caminos, o huellas, sirven para caminar y llegar de un lado a otro, ¿Por qué habrán sido importante los caminos para los romanos? ;Ah! Es que ellos tenían muchos caminos, así que podían llegar a cualquier lado. ¿Si? Si tío, lo vi en el dibujo del libro.

Luego de esto hubo un diálogo más, pero lo que en ese momento no podía dejar de mirar, era el rostro de la profesora. Se veía incrédula al observar a su estudiante problema entrar en una dinámica reflexiva y de pensamiento, para la cual su único obstáculo era la ausencia del vocabulario requerido y la ineficiencia de su mediador. Casos como este he presenciado muchos en mis distintas experiencias educativas, pero la gran mayoría de ellas han sido en espacios desescolarizados. Luego vuelvo al rostro del estudiante, también incrédulo de lo que acababa de hacer, pero con una sonrisa que para mí reflejaba la alegría de haber aprendido algo, y sin tener que haber hecho una tarea para ello. ¿Nos damos el tiempo de conocer cómo piensa y qué conoce cada niño o niña? ¿Por qué es tan fácil caer en la acción o pensamiento de culpar a los niños por sus dificultades de aprendizaje? En momentos como ese reafirmo la importancia de estar atento, de estar alerta, y decidí que si la escuela no me permitía vivir esos tiempos, si me dificultaba hacer esas mediaciones, pues no trabajaría en una escuela, ya que es muy fácil olvidarse de esto y justificarse, no quería hacerlo, no quería resignarme a posibilidades tan restringidas.

Mi primer intento por desobedecer lineamientos generales de la escuela y ministerio para hacer lo que creía más pertinente al grupo, fue con un segundo básico en una escuela municipal. Me enviaron a reemplazar a un profesor por dos meses lo que valdría como mi práctica profesional de la universidad y antes de entrar a la sala me dicen que quieren que 
los niños y niñas tengan un buen puntaje en el SIMCE de lenguaje y que debería aplicar algunos de los programas ministeriales como la lectura silenciosa y aplicar ensayos. Luego de un par de días con el curso, generé un levantamiento de información que me arrojó un diagnóstico muy poco favorable para los deseos de la dirección. Catorce niños de los cuales cinco habían repetido, solo cuatro sabían leer, otros dos decodificaban silábico, no se sentaban uno al lado del otro ya que su costumbre era pelear y carecían de herramientas para poder solucionar sus problemas de otras maneras. El dato que me dio la pista para pensar en una estrategia fue la cifra de hacinamiento, un porcentaje casi del $100 \%$ vivía en esas condiciones. ¿Qué repercusiones tiene en la formación de la mente y las emociones de los niños vivir en condiciones de hacinamiento? ¿Cómo se relaciona con todos los otros factores que se puedan detectar, como la pobreza, la naturalización de la violencia, el historial de fracaso escolar y la imposición de contenidos para nada relacionados con su presente? Fue un desafío importante que me costó varias noches de artículos de psicología y de búsqueda de experiencias de profesores para el desarrollo de la resiliencia. Finalmente aventuré una modificación radical en el currículum, abandoné los horarios y las asignaturas y me dediqué a tomar algunos de los objetivos de aprendizaje como pretexto para fortalecer su sentido de identidad y pertenencia. Al paso de tres semanas el grupo ya se sentaban más unidos y cuando proponía alguna actividad relacionada con las matemáticas o la lectura, su disposición y su capacidad de estar presentes, era mucho más favorable, fue increíble el cambio. ¿Qué pasó conmigo? Pues, me costó discusiones gigantes con la UTP y Dirección, y además casi me reprueban la práctica profesional por no presentar las planificaciones de la forma en la que se acostumbra en un contexto escolar "normal". Si no fuera por un documento interminable que daba sustento teórico y pedagógico a mi propuesta, y una profesora de la universidad que confió en mi trabajo, creo que la habría reprobado. ¿Tuve suerte? No sé, pero creo que el trabajo de buen nivel profesional y expuesto en los lenguajes que los que toman las decisiones hablan, tiene altas probabilidades de ser acogido, por muy distinto a la norma que sea. ¿Seremos los profesores en las escuelas los que estamos olvidando nuestra profesión? ¿Cómo es posible que no se nos ocurran estrategias pedagógicas para revertir las dificultades que tienen familias en su diario vivir? 
¿Cómo es posible que no potenciemos lo que hacen niños y niñas bien por nublarnos con objetivos que no son pertinentes a los contextos?

Suelo pensar en que el ego docente afecta sutil y profundamente en las dinámicas de aula, pero solo a aquellas que buscan el desarrollo de la autonomía y el fortalecimiento de la curiosidad. Nunca olvidaré uno de mis días más felices como profesor, uno que ocurrió en un aula de escuela particular subvencionada, de estas que se destacan por su alta exigencia y por clases monótonas porque según ellos, ya encontraron la receta. Mi paso por esa escuela fue en otro reemplazo luego de hacer una buena práctica universitaria. En el séptimo la asignatura de historia siempre había tenido una rutina fija: Exposición del profesor, guía con información y preguntas; revisión de la guía y nueva exposición; y luego una prueba. Los niños aprendían rápidamente los conceptos que le iban a preguntar y con eso se aseguraban un buen rendimiento. Siempre había un par de estudiantes que preguntaban un poco más, ellos llamaron mi atención cuando observaba, y con ellos me apoyé cuando me correspondió hacer la clase. Generé un planteamiento didáctico diferente al que tenían, comenzando por un listado enorme de preguntas que ellos hicieron, luego categorizándolas y organizando una indagación bibliográfica, con una posterior experimentación para las hipótesis que planteaban como posibles respuestas a sus preguntas. Durante las clases mi presencia era casi imperceptible. Al finalizar la unidad, una niña me dice un poco contrariada: Profe, en su clase he aprendido muchísimo, pero usted no me ha enseñado nada. He ahí, uno de los días más felices de mi vida como profesor, una niña descubriendo que puede aprender sin que alguien le enseñe y disfrutarlo al mismo tiempo. Obviamente mi estilo no le agradó al colegio, aunque el profesor al que reemplacé me dijo que había reflexionado mucho sobre su forma de hacer clases al ver la motivación de los niños con esta forma distinta. ¿Qué pasaría si dejamos a los niños y niñas hacer las preguntas? ¿Qué pasaría si no nos dedicamos a responder esas preguntas sin antes acompañarles en los caminos reflexivos que pueden provocar que emerjan aprendizajes más potentes y complejos aún? ¿Qué pasa si el profesor deja de buscar el protagonismo en el aprendizaje de los demás? 
Es comprensible querer esa retribución, de sentir que tú enseñaste, de sentir que si no fuera por ti, él o ella no habrían aprendido, pero creo que es algo que hay que soltar para poder dejar espacio a que el potencial de aprendizaje y la autonomía se expandan en cada uno de nuestros estudiantes. El trabajo es desgastador y poco reconocido, pero es cosa de paciencia, las retribuciones no tienen que buscarse en desmedro de la autonomía.

Otros factores que atentan contra el desarrollo de la autonomía y la búsqueda del aprendizaje en las escuelas son el miedo, la amenaza y la condena hacia el error. Un día estaba en la biblioteca de una escuela municipal redactando informes de observación y entra un grupo de estudiantes que tenían que desarrollar una guía de matemáticas allí, ya que su profesora no había venido ese día. No pude evitar ofrecerles mi ayuda por si la necesitaban, pero les advertí que de mí no obtendrían respuestas. Me acerco a un niño de séptimo y le explico algunos procedimientos luego le pregunto: ¿Entendiste? - Si. ¿Me explicas cómo entendiste? Lo que fue seguido de un silencio. Tranquilo, yo no pongo notas ni te voy a decir nada si no sabes, pero necesito saber si mi explicación no te sirvió para intentarlo de otra manera, lo importante es que aprendas, pero para eso debes ser sincero sobre si tienes dudas o no, de todas maneras sino quieres hacer nada, no hay problema, pero acá estoy para ayudarte. Luego de eso su cara cambió drásticamente y me dijo: Tranquilo tío, lo intentaré una vez y le pregunto, es que siempre me retan cuando no entiendo. Esa vez terminó estudiando hasta el recreo, me preguntó varias veces si lo que hacía estaba bien o mal, pero fue un hermoso momento cuando salió de la biblioteca, luego volvió y me agradeció: Gracias tío, ahora me quedó clarito.

Esta historia debe ser muy común entre los profesores, pero a pesar de lo común de estas historias cabe preguntarse ¿Por qué cuando el estímulo/castigo de la calificación desaparece también desaparece el interés? ¿Por qué cuando no hay calificación desaparece también el miedo al error? ¿Cuál es el beneficio real de las calificaciones al sistema escolar? ¿Cuándo esa conexión con los estudiantes dejará de ser una anomalía en el cotidiano de las aulas?

Con estas tres historias quería reafirmar las ideas que me venía formando desde mi época escolar. La escuela está mal pensada, se realizan prácticas que anulan la capacidad de 
pensamiento y reproducen las desigualdades sociales sin mayor efecto transformador. El bajo nivel profesional que se puede alcanzar en las deficientes condiciones laborales docentes que se potencia con la escolarizada formación universitaria. Las anticuadas y desarticuladas didácticas que se practican en las aulas, que en lugar de favorecerse de las energías y formas en las que naturalmente aprendemos, se olvida el juego, el diálogo, la pregunta, el error y la experimentación. Hay que estimular la curiosidad y hay que hacerlo de tal manera, que cuando se tenga que escribir sobre cosas que pasan muy pocas veces en la escuela, se escriba sobre niños que pierden el interés en aprender o de niños que pierden su motivación.

Algo anda mal, el dolor de la escolarización en nuestros jóvenes y en los adultos, es evidente, pero aún estamos a tiempo de hacer algo, de continuar la labor de tantos educadores y educadoras que han hecho de su vida un ejemplo para los profesores.

\section{Primer desvío: hacia nuevas montañas}

Cuando llegué a la universidad, el primer semestre ya quería irme, era todo tan cuadrado, tan fácil, no había ni desafío ni motivación, hasta que encontré el primer ejemplo de proyecto pedagógico que se hacía coherente y sin permiso. Una de las primeras salidas de carretera que tuve y cuyo sendero me enseñó a viajar de verdad por este territorio de la educación. Sentí que podía hacer lo que sentía que tenía que hacer, sin permiso, solo con fuerte organización y autogestión. Este sendero fue el del Semillero de Investigación en la Universidad de La Serena. Ahí aprendí que podía aprender de otras maneras lo que sentía que necesitaba sin que nadie me lo tuviese que enseñar, aprendí a dejar la crítica que me inmovilizaba y a experimentar la iniciativa y la propuesta que me movilizaba a hacerme cargo de esas críticas. Claramente una experiencia que me liberaría al convencerme de que era posible otra forma de educar-nos.

El Semillero es una instancia de diálogo y reflexión del que participan estudiantes y académicos de la universidad, con quienes habitualmente organizamos seminarios, charlas, publicaciones, pasantías e investigaciones. A partir de ese espacio logré encontrar muchas otras posibilidades para desenvolverme como educador sin tener que ir irremediablemente a una escuela y tener que reproducir modelos pedagógicos en los que no creo y que además 
he vivido la experiencia en ellos, creyendo fuertemente que no funcionan. Desde el semillero logré conocer experiencias educativas en Brasil y Colombia, todos proyectos innovadores y con un discurso pedagógico potente. Proyectos que emergieron de grupos de valientes educadores que convencidos de que otra forma de educar es posible y necesaria, comenzaron con sus propias escuelas. En estos viajes mi mente se fue abriendo y absorbiendo un sinfín de experiencias y propuestas pedagógicas, es posible otro camino, no seré el primero, ni el último. ¿Por qué no todos los estudiantes de pedagogía viven un tiempo en el extranjero para aprender a deshacernos de nuestro etnocentrismo? ¿Por qué no es parte del currículum universitario el conocer la diversidad de proyectos educativos, incluso aquellos que desafían los lineamientos oficiales?

\section{Segundo desvío: adentrándose en los bosques}

Cuando comencé a alejarme de la escolarización, empecé a encontrarme con muchas experiencias hermosas de aprendizaje, al comienzo me sentía constantemente maravillado. Luego con el tiempo he ido observando que en realidad si bien es fascinante y hermoso ser testigo de ese momento en el que los ojos brillan y fulguran de emoción luego de haber realizado una buena pregunta o descubrir un patrón en la naturaleza, esto es más cotidiano de lo que la escuela me había acostumbrado. La propensión al aprendizaje del ser humano requiere de muy pocos elementos para llevar a niños, niñas y jóvenes a desarrollar aprendizajes y preguntas que lo maravillen, solo basta una compañía mediadora e intencionada para potenciar aún más esos intereses y energías.

Uno de los desafíos más bellos a los que me he enfrentado (y disfrutado) caminando lejos de la carretera de la escolarización, es el grupo de voluntariado comunitario que realizo desde ya hace cuatro años en una población de La Serena. Imagínense: Llegas a un espacio que habilitó una vecina para que apoyes en sus estudios a niños y niñas del barrio. Llegan entre ocho y quince niños y niñas entre los tres y los dieciséis años a solicitar ayuda en sus estudios de casi todas las asignaturas del currículum oficial, y tu educador, sin planificación, sin libros, sin tiempo para generar una unidad multigrado, con todas las expectativas de los jóvenes y sus familias en tu capacidad de profesor. Cada sábado mi cerebro está al borde del colapso por procesar tanta información al mismo tiempo, tratando 
de indagar en algunos aspectos de las vidas de cada uno/a y apostar todo al estilo mediador. Promover el sentido y significado, la trascendencia a través de la intencionalidad pedagógica es la herramienta más potente que he logrado adquirir como educador, y en estos espacios en los que no hay horario ni límites, es lo que me ha salvado. Allí aprendí a mediar aprendizajes con lo que tuviese a la mano, aprendiendo de paso que la manera de preparar una sesión de clases o mediación, es ser extremadamente riguroso con la propia preparación, no siempre habrá libros, ni internet, ni lápices ni papel, pero siempre se puede dibujar en la tierra o desarrollar un profundo diálogo, experimentar con el mundo circundante. Reitero, no hacen falta muchas cosas para que la propensión a aprender del ser humano llegue a despertar aprendizajes profundos, trascendentales, solo por fluir con las formas en las que cada uno/a aprende, sin tratar de controlarlo todo. ¿Cuándo soltaremos el afán controlador? ¿Cuándo entenderemos que nada está bajo control? ¿Cuándo será que aprendamos a reconocer los patrones que hay en nuestro vivir para poder caminar por la vida con mayor coherencia, en lugar de diseñar caminos prestablecidos y rectos que terminan por no hacer una correcta lectura del contexto? El educador podría ser como un buen capitán de barco a vela, más o menos sabe a dónde podría llegar, pero no se va en línea recta y con las velas abiertas todo el camino, siempre está leyendo la marea, los vientos, aprende a predecir pero sabe que no lo puede controlar, solo queda prepararse bien y vivir en el tiempo presente con la mente y corazón también puesta en el futuro.

Y claro, dejar de intentar controlar los procesos es realmente difícil, carecemos de la confianza en los otros y la experiencia en sistemas de educación que tengan mayores libertades. En el último tiempo me he dedicado a tratar de comprender qué es lo que mueve a los niños, niñas y jóvenes con los que comparto los espacios y tiempos educativos, quiero ir más allá de la clara evidencia de que les gustan los videojuegos, conversar a través de sus teléfonos y subir fotografías a internet. ¿Qué necesidades están tratando de cubrir con esas acciones? ¿Qué curiosidades tienen cuando hacen lo que hacen? Si tuviesen alternativas ¿Dejarían sus vicios para satisfacer de otras maneras sus necesidades? ¿Qué es lo que desea un niño de cinco, de siete, de once, de catorce, de dieciséis años? 
No puedo pasar de este tema sin narrar una de las experiencias más divertidas y clarificadoras que me he presenciado. En una asamblea de padres y madres en un espacio educativo "alternativo" en el que trabajé dos años, se debatía el tema del uso de la tecnología (un título más bien eufemístico para conversar sobre la prohibición de teléfonos celulares y videojuegos). Como yo estaba a cargo del grupo de los adolescentes siempre los invitaba a ser parte de esas asambleas, y en esa ocasión sentí que fue una de las mejores decisiones. Los padres y madres comenzaron las locuciones sobre lo dañino que era para los niños usar el teléfono, que les preocupaba que pasaran tanto tiempo en Facebook y Whatsapp, o que jugaran videojuegos. Cuando ya estaban por llegar a una decisión, una de las niñas (catorce años) levanta la mano y pide hablar: No sé porque les molesta tanto que usemos nuestros teléfonos, ¿Se han dado cuenta de que si no fuera por ellos nuestra interacción con otras personas sería muy poca? Pasamos muchas horas en la escuela, mis amigos más cercanos viven a un par de kilómetros y yo solo quiero alguien con quien conversar, pero lógicamente no me darán permiso tampoco para faltar a la escuela y salir con ellos, o para visitarles cada día después de la escuela porque la ciudad es un lugar peligroso, no podemos ir solos y ustedes tampoco tienen tiempo como para acompañarnos. Luego se quejan de que somos antisociales. Creo que no pude disimular mi felicidad, estaba tan feliz de ver como una niña que llevaba un tiempo conmigo y que se solía mostrar tímida, sacara la voz para validar su vivencia y para no permitir que otros, sin entenderle, decidieran sobre su vida. Luego, culmina su elocuente discurso diciendo: Si pudiera pasar más tiempo conversando con mis amigos sin necesidad del celular, creo que de verdad no lo usaría tanto y no estarían hoy con miedo a que pierda mi futuro por estar frente a la pantalla.

¿Qué hay detrás de un discurso de este tipo? ¿Ponemos atención a lo que de verdad buscan los niños y niñas? ¿Por qué frente a algo que no podemos controlar emerge el miedo en lugar de la curiosidad y la empatía? ¿Tendremos la sabiduría suficiente para pensar espacios y tiempos educativos que usen esas motivaciones de los jóvenes para favorecer su propio desarrollo, aprendizaje y crecimiento personal? ¿Será el fluir con los vientos del interés de cada niño y niña lo que nos indique el camino para transformar la educación y la sociedad? Es tiempo de sentarse un momento a pensar otra forma de organizar las 
instituciones educativas, no es posible que siempre estemos luchando contra la corriente o siguiendo carreteras sin sentido.

Cuando nos sentamos a reflexionar sobre nuestras estrategias pedagógicas en esos días en los que aparentemente no nos resulta nada, regreso a esas vivencias y experiencias, esas que me recuerdan lo humano y lo que he aprendido sobre nosotros. La ansiedad y la paciencia siempre están en una constante lucha, pero cuando he optado por la paciencia, casi siempre he vivido grandes satisfacciones. La clave está en confiar en los demás.

En este ámbito, uno de los aprendizajes más lindos que me han dado las experiencias como educador fuera de la escuela, es la de poder validar a los estudiantes en sus momentos emocionales y sus creencias. Dialogar con ellos, proponer en lugar de imponer, acompañar en lugar de guiar, mostrarse humano. Tengo un inesperado record personal de no pasar una semana sin acompañar un momento emocionalmente fuerte, casi siempre en su expresión de llanto. ¿Es tanto el dolor de la escolarización que los niños y niñas luego no pueden dejarla sin sufrir? ¿Es tanta la necesidad de acogida por parte de los adolescentes, que apenas tienen una opción de ser oídos sin juicios y abrazados sin expectativas lo aprovechan y se muestran desbordados por su emoción? ¿Es viable un sistema escolar que obliga a los jóvenes a omitir sus emociones y continuar funcionando para los objetivos de la escuela?

He ido observando que cuando les escucho y acepto que en un determinado momento quieren conversar, o estar solos y oír música, o salir a caminar con un compañero, preparase un té y acurrucarse bajo una frazada, tomar la guitarra y tocar acordes al azar, u otras tantas formas de estar mientras se resuelve un estado emocional que los inquieta, posterior a que logran retornar a su centro emocional, regresan más concentrados y con mayor disposición a desarrollar sus objetivos o cumplir sus compromisos. Pero cuando yo no me percato de eso o ellos mismos se autoexigen a seguir a pesar de no sentirse bien ni cómodos, solemos encontrar muchas barreras que culminan con frustración y tedio por parte de ellos, y por mi parte con una sensación horrible de no haber tenido el ojo lo suficientemente fino para poder mediar en ese momento. Hay que confiar en ellos y ellas, la reciprocidad a esa confianza será una apertura más grande a nuestras preguntas y 
sugerencias, más posibilidades de conocerles. Nunca olvidaré cuando uno de mis estudiantes que siempre había desertado de las escuelas y evitaba lo más posible los compromisos me dice: Hacer esto me pone realmente incómodo y nervioso, pero si tú crees que al hacerlo podré aprender, confiaré en ti y lo haré. Ese día sentí el peso de mil mochilas en mi espalda, pero creo que de eso se trata esto, de generar vínculos tan importantes que podemos confiar los unos en los otros al punto de atreverse a hacer cosas que normalmente no haríamos, a dar esos pasos fuera de nuestra zona de comodidad, a explorar territorios nuevos y a aprender de esa experiencia, con sus errores y sus aciertos. Aceptemos que somos seres emocionales, aceptemos que los niños y niñas requieren de un ambiente que les respeto sus emociones, aprendamos sobre ellas y vivamos de manera coherente con ese saber. ¿Por qué nos cuesta tanto confiar en que si nos salimos un poco de la ruta trazada por hacer caso al momento emocional, podemos de todas maneras llegar a destino? ¿Por qué seguimos obsesionados con los tiempos cronológicos?

Cuando me detengo a pensar sobre los tiempos, de verdad sufro. Son demasiadas las contradicciones que conviven en mí respecto a este tema, la constante tensión y preocupación porque los objetivos no se logran en los momentos que a uno le gustaría suele generar mucha angustia. Pero con el pasar de los años y la experiencia de educador, voy aprendiendo día a día sobre esto, y voy adquiriendo más destreza para percibir el fluir de los tiempos de los demás. Recuerdo cuando uno de los niños más desafiantes pero juguetones del espacio educativo alternativo en el que trabajé no quería entrar a la sala, luego de varios llamados decidí ir a buscarlo. Estaba jugando a ser perro, pero en ese momento estaba "bravo", ladraba y se oponía a los llamados, por lo que decidí mirarlo fijamente a los ojos y lanzar un ladrido que me posicionara como el nuevo alfa. Su reacción fue tan natural como divertida, de inmediato, hace un gemido de perro y se va corriendo en cuatro patas hacia la sala. ¿Es posible entrar en el tiempo del juego y la fantasía de los niños? ¿Es posible coordinar los tiempos y respetar los ritmos de cada niño en un espacio educativo? ¿Estamos dispuestos a aprender y aplicar lo aprendido sobre estos ritmos?

Siempre está latente el temor a no alcanzar a cumplir los objetivos, yo creo que debemos expandir nuestra visión temporal y re-pensar nuestras estrategias. Recuerdo un 
diálogo sostenido con un estudiante bajo un palto que teníamos en el patio. Este joven no había hecho ninguno de los trabajos y en realidad, nunca había entrado a la clase por más de cinco minutos. Yo salí del salón un día y lo invité a conversar, me contó que pensaba que él era tonto y que no sabía nada, yo por supuesto me sentí desafiado a revertir esa creencia, pero no con un discurso motivacional, sino con una demostración. En la clase estábamos realizando silogismos, y él percibía la tarea como demasiado compleja, por lo que decidí guardar unos minutos de silencio y luego preguntarle por su fin de semana. El solía salir a cazar y me narraba con gran cantidad de detalles y conocimientos todo lo que hacía. Luego de unas preguntas intencionadas, terminó dándose cuenta de que había realizado varios silogismos en nuestra conversación y que lo había hecho solo. Fueron aproximadamente diez minutos en los que se logró el objetivo que se había evadido durante un mes. Una potente demostración del poder de los diálogos y de la mediación solo para tomar conciencia de los aprendizajes, imagínense para enseñar. En ese mismo palto recuerdo cuando una estudiante llega corriendo a decirme que cuando salía de la ducha había logrado entender la refracción de la luz. Ella aparentemente no había hecho nada durante días, pero su mente estuvo trabajando todo el tiempo y llegó ese momento mágico en el que algo en su experiencia cotidiana permite hacer las conexiones necesarias y lograr un establecimiento de relaciones nuevo para ella. Su expresión de felicidad fue lo mejor.

Los espacios y tiempos no escolarizados son todo un desafío, pero lo son aún más para quienes ya vienen con aprendizajes muy arraigados en su periodo de escolarización. ¿Se imaginan que todo lo que hacían para obtener éxito en la escuela, ya no te sirviera más? ¿Tener que tomar tus propias decisiones sobre que aprender o hacer? ¿Manejar tu tiempo y tu voluntad para cumplir tus metas porque nadie te exige nada? Deshacerse de la escolarización es un proceso complejo y no libre de dolor, pero enfrentarse a ese lienzo nuevo donde dibujar tus nuevas formas y pensamientos, tampoco es nada fácil. Al acompañar a niños y niñas en ese proceso he tenido que desarrollar una gran fortaleza emocional y también mucha habilidad para contener, es un proceso largo y emocionalmente fuerte, y quién contiene debe estar lo más estable posible. El autoconocimiento del educador pasa a ser una prioridad para el trabajo cotidiano de acompañamiento. 
Un momento donde hemos puesto a prueba la confianza y la sabiduría de los jóvenes para reflexionar sobre su vivencia emocional y capacidad de autoconocimiento, es en los rituales de evaluación que hemos desarrollado. La dinámica consiste en escoger algunos ámbitos para autoevaluarse, para evaluar el proyecto educativo, para evaluar a los educadores, para evaluar las didácticas y para evaluar a sus compañeros y compañeras. Son días intensos de evaluación que culminan con un ritual donde respetuosamente todos leen sus autoevaluaciones y escuchan lo que los demás evalúan de ellos. Suelen ser los días en los que más emoción siento al verlos entrar en una dinámica reflexiva con una empatía y asertividad hermosa, usando todas las herramientas lingüísticas y emocionales para dar la retroalimentación más sincera posible a sus amigos y amigas. Gracias a eso han crecido mucho en su autonomía y convivencia. La propensión a aprender del ser humano se ve fuertemente potenciada por la posibilidad de llevar al plano consciente la experiencia, y cuando ellos y ellas comienzan a reflexionar sobre su hacer y su actuar, su modificación es impresionante. Y así vamos, aprendiendo sobre los tiempos y los ritmos, observando a jóvenes aprender a resolverse y a seguir, a reflexionar, dudar, entrar en crisis, resolverse y seguir. Observando como rara vez una conversación termina, ya que cuando reflexionamos sobre algún tema, en el momento no emergen demasiadas opiniones, pero al pasar de los días comienzan a regresar y a tener más forma. Yo aprendo y ellos aprenden, aprendemos a habitar nuestro espacio común y a respetar nuestros tiempos particulares. ¿Cuánto sabemos de nuestros propios ritmos? ¿Seremos capaces de diseñar espacios y tiempos educativos que se coordinen respetuosamente con los intereses y tiempos de quienes habitan ese espacio?

Y por último, vuelvo a reafirmar que si bien en la educación escolar algo anda mal, mientras menos forcemos los procesos, más fácil estos se van a desarrollar, y es posible hacerlo. Recuerdo muchas situaciones en las que se quiere enseñar algo o motivar a los niños a hacer algo en un momento determinado, y por lo general un alto porcentaje presenta resistencia a la propuesta. Típico niño que se la pasa dibujando, pero cuando le solicitan que dibuje, no quiere hacerlo, y así muchos ejemplos más en los que cuando algo interesante suena como a tarea o a obligación, o se impone en un tiempo en el que no hay interés o ganas, genera oposición. He visto en el último año como mi estrategia de diseñar 
el espacio activo modificante (López de Maturana, 20014) intencionadamente y de aprovecharlo como creo que podrían aprovecharlo también los niños, ha servido. El día que dejé tableros de ajedrez a disposición y logré convencer a uno de que jugara conmigo mientras los demás estudiaban, comenzó la moda del ajedrez. Muchos aprendieron a jugar y se pasaban horas en ello. Lo mismo pasó con la música, ya que solo bastó dejar un par de guitarras en la sala, para que en unas semanas todos estuviesen aprendiendo a tocar guitarra, cuando digo todos, es todos. Pero cuando se organizó un taller de guitarra, no querían hacerlo.

Es bueno aprender sobre estas dinámicas, por eso cierro volviendo a lo que compartí a modo de introducción. La educación es un territorio dinámico, cambiante, con muchos factores que influyen en ella, y es más coherente caminar por ella estando atento, improvisando con los aprendizajes que se obtienen en el caminar, que solo se dan en la confianza con la comunidad y no por esa ruta prestablecida y estática, que no se adapta a las transformaciones del territorio. La idea es caminar sin ruta definida pero con rumbo claro, como quien explora una montaña nueva sin saber por dónde caminará, que observa el contexto para poder orientarse de la mejor manera en el momento presente, pero sabe que quiere llegar a la cima en el futuro.

\section{Referencias bibliográficas}

Calvo, C. (2007). Del mapa escolar al territorio educativo: disoñando la escuela desde la educación, Santiago: Editorial Nueva Mirada.

López de Maturana, S. (2014). Maestros en el territorio, La Serena: Editorial de La Universidad de La Serena. 